\title{
Ecologia da polinização da cactácea Arrojadoa rhodantha em caatinga hiperxerófila
}

Lúcia Helena Piedade Kiill $^{1 *}$, Amanda Pricilla Batista Santos ${ }^{1,2}$, Carla Tatiana de Vasconcelos Dias Martins ${ }^{1}$, Nerimar Barbosa Guimarães da Silva ${ }^{3} \&$ Tamires Almeida da Silva ${ }^{1}$

${ }^{1}$ Embrapa Semiárido, BR-428, Km 152, s/n, Zona Rural, C.P. 23, 56302-970, Petrolina, Pernambuco, Brasil.

${ }^{2}$ Universidade de Pernambuco, BR-203, Km 2, s/n, Campus Universitário, Vila Eduardo, Petrolina, Pernambuco, Brasil.

${ }^{3}$ Universidade Estadual de Feira de Santana, Avenida Transnordestina, s/n, Novo Horizonte, 440036-900, Feira de Santana, Bahia, Brasil.

Ecologia da polinização de Arrojadoa rhodantha

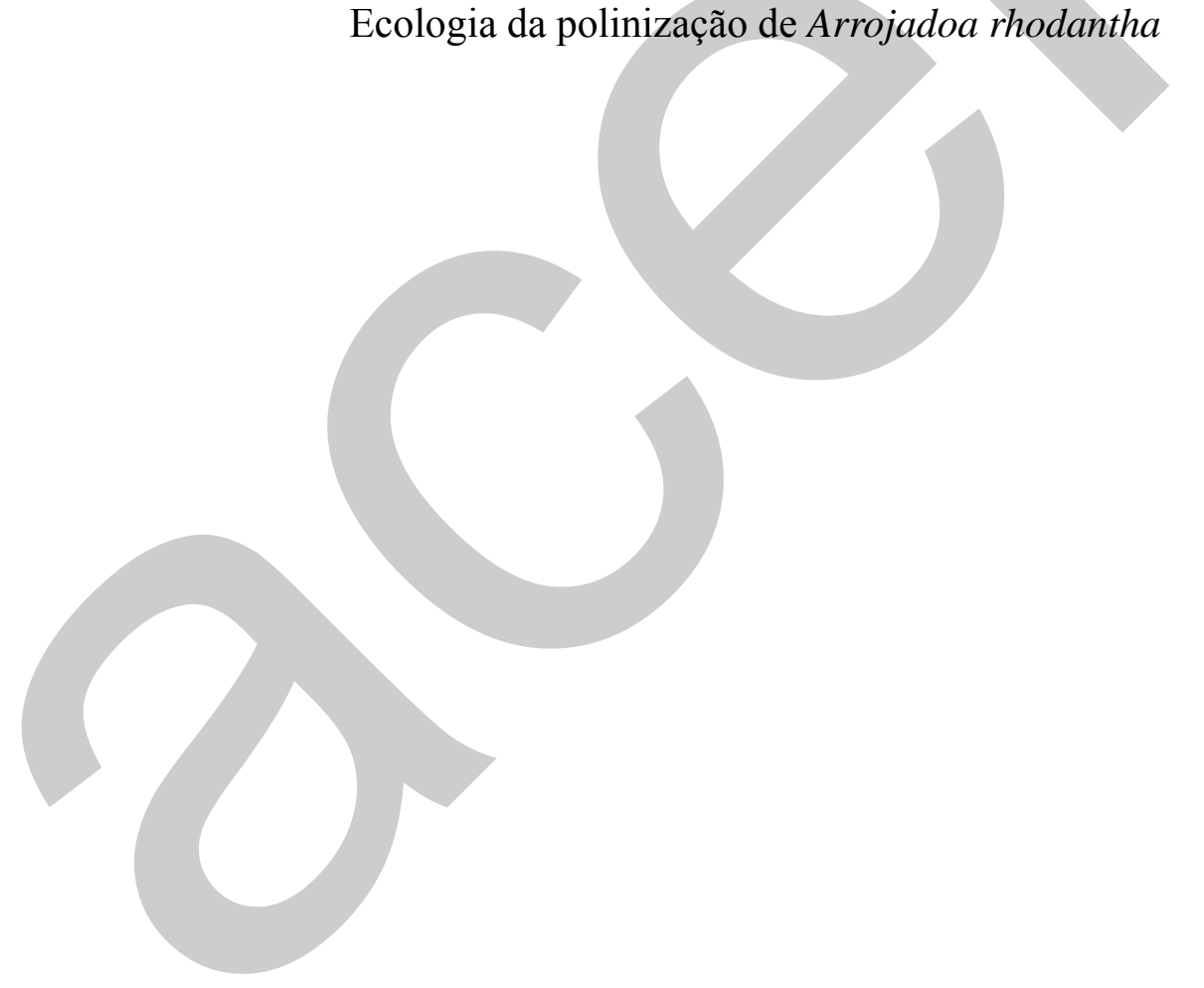

*Autora para correspondência: kiill@cpatsa.embrapa.br

Editor responsável: Clemens Peter Schlindwein

Submetido em 21 dez. 2011; publicação eletrônica: 25 dez. 2012 
Resumo - Arrojadoa rhodantha (Cactaceae) é uma espécie amplamente distribuída na Caatinga. Devido ao desmatamento, no entanto, suas populações vêm sofrendo redução considerável, tanto em termos de distribuição como de abundância. Nós estudamos a fenologia reprodutiva, a biologia floral e o mecanismo da polinização de A. rhodantha visando fornecer informações sobre a ecologia da polinização dessa espécie. O estudo foi conduzido entre agosto de 2010 e julho de 2011, em uma área de caatinga em Petrolina, Pernambuco, em 15 indivíduos de $A$. rhodantha, com 35 h esforço amostral para a observação de visitantes florais. As fenofases de floração e frutificação ocorreram durante o ano todo, com maior produção de flores e frutos no período chuvoso. As flores são magenta; elas se abrem por volta de $04 \mathrm{~h} 00$ e se fecham em torno de $23 \mathrm{~h} 00$. Foram visitadas por beija-flores ( 3 espécies), abelhas (3), moscas (1) e borboletas (1). As abelhas Trigona spinipes, Friseomelitta doederleini e uma Halictidae foram os visitantes florais mais frequentes (93,16\% das visitas). Os beija-flores, considerados polinizadores potenciais dessa cactácea, foram responsáveis por 6,18\% das visitas, sendo Eupetomena macroura a espécie mais frequente. Abelhas, moscas e borboletas Phoebis philea foram classificadas como furtadoras de néctar/pólen ou pilhadoras de pólen. Arrojadoa rhodantha produziu frutos apenas em condições naturais (55\%) e por xenogamia $(35,3 \%)$. Por apresentar padrão de floração e frutificação contínuo, esta espécie pode ser considerada uma importante fonte de alimento para a fauna da Caatinga, onde existe sazonalidade na disponibilidade de fontes de alimento.

Palavras-chave adicionais: Cactaceae, Eupetomena macroura, ornitofilia, xenogamia.

Abstract (Pollination ecology of the cactus Arrojadoa rhodantha in a seasonal hiperxerophilous tropical forest) - Arrojadoa rhodantha is a widely distributed species in the Caatinga. Due to deforestation, however, their populations have suffered considerable reduction both in terms of distribution and abundance. We study the reproductive phenology, floral biology and pollination mechanism of $A$. rhodantha to provide information about the pollination ecology of this species. The study was conducted between August 2010 and July 2011, in a caatinga area, municipality of Petrolina, Permanbuco State, Brazil, with 15 individuals of $A$. rhodantha and a sampling effort of $35 \mathrm{~h}$ observing floral visitors. Stages of flowering and fruiting occurred throughout the year, with greater production of flowers and fruits in the rainy season. The flowers are magenta, opening at around 4:00 a.m. and closing at 11:00 p.m. They were visited by hummingbirds ( 3 species), bees (3), flies (1) and butterflies (1). Trigona spinipes, Friseomelitta doederleini and a Halictidae were the most common 
floral visitors (93.16\% of total visits). The hummingbirds are considered potential pollinators of this cactus, but accounted for only $6.18 \%$ of total visits, and Eupetomena macroura was the most frequent species. Bees, flies and the butterflies Phoebis philea were classified as nectar/pollen thieves or pollen robbers. Arrojadoa rhodantha produced fruits only in natural conditions (55\%) and by xenogamy (35.3\%). Because of the continuous flowering and fruiting, this species can be considered as an important source of food for the fauna from the Caatinga, where there is seasonality in the availability of food sources.

Additional key words: caatinga, Cactaceae, Eupetomena macroura, ornithophily, xenogamy. 
A família Cactaceae possui cerca de 1.500 espécies e 124 gêneros com distribuição neotropical, principalmente nas áreas quentes e secas (Hunt et al. 2006), sendo a segunda família de angiosperma mais representativa em espécies endêmicas da região (Taylor \& Zappi 2004). O Brasil é considerado o terceiro maior centro de diversidade de Catactacae, com 35 gêneros e 240 espécies, das quais $22 \%$ são apontadas como raras e mais de $80 \%$ são endêmicas (Machado 2009). Para a Caatinga, são registradas 58 espécies de Cactaceae, muitas delas endêmicas e carecem de informações sobre sua biologia floral e reprodutiva (Taylor \& Zappi 2004).

De modo geral, os representantes de Cactaceae são plantas xerofíticas, áfilas, com caule e ramos suculentos, fotossintetizantes e espinhosos, e com flores solitárias e vistosas. Na literatura (Locatelli \& Machado 1999a,b; Rocha et al. 2007), é descrita uma diversidade de sistemas de polinização, apontando uma gama de animais como polinizadores. Porsch (1939) estabeleceu cinco biotipos florais para a família, adotando aspectos relacionados ao horário da antese, à morfologia floral e aos visitantes observados (besouros, abelhas, aves, mariposas e morcegos). A ornitofilia foi associada aos gêneros Arrojadoa Britton \& Rose, Cleistocactus Lem., Melocactus Link \& Otto, Opuntia Mill. e Tacinga Briton \& Rosen por apresentarem flores tubulosas, inodoras, de coloração vistosa e com separação entre os órgãos sexuais e a fonte de alimento (Faegri \& van der Pij1 1979).

No Brasil, cactáceas ornitófilas foram registradas na Mata Atlântica (Buzzato 1995), na Caatinga (Raw 1996; Locatelli \& Machado 1999a) e em Campo Rupestre, (Aona et al. 2006; Colaço et al. 2006). Na Caatinga, a ornitofilia foi observada em Melocactus salvadorensis Werderm, com registro de visitas do beija-flor Chrysolampis mosquitus Linnaeus, 1758 (Trochilidae) (Raw 1996). Nas observações em Melocactus zehnteneri (Britton \& Rose) Luetzelb. e Opuntia palmadora Britton \& Rose [= Tacinga palmadora (Britton \& Rose) N.P.Taylor \& Stuppy], Locatelli \& Machado (1999a) constataram que as duas cactáceas partilhavam o mesmo polinizador (Chlorostilbon aureoventris Boucier \& Mulsant, 1948; Trochilidae). A polinização pela mesma espécie de beija-flor foi observada em Micranthocereus flaviflorus Buinning \& Brederoo e M. streckeri Heek \& Criekinge (Aona et al. 2006), e também considerada para Melocactus glaucescens Buinning \& Brederoo e $M$. paucispinus Heimen \& Paul (Colaço et al. 2006).

Arrojadoa é composto por cinco espécies, sendo característico do agreste, campos rupestres e cerrado. A ornitofilia é apontada como síndrome de polinização de suas espécies (Taylor \& Zappi 2004), mas a polinização por aves ainda não foi confirmada. Dentre as 
espécies do gênero, A. rhodantha (Gürke) Britton \& Rose apresenta ampla distribuição na Caatinga, ocorrendo nos estados do Piauí, Pernambuco, Bahia e Minas Gerais. Devido ao desmatamento, no entanto, suas populações vêm sofrendo redução considerável, tanto em termos de distribuição como em abundância (Zappi et al. 2011).

O presente trabalho apresenta informações sobre fenologia reprodutiva, biologia floral e mecanismo da polinização de Arrojadoa rhodantha (Gürke) Britton \& Rose em caatinga hiperxerófila. Buscou-se responder as seguintes questões: 1- Qual é o padrão fenológico desta espécie na área de estudo? 2- Quais são os visitantes florais e potenciais polinizadores desta planta? e 3- Qual é a estratégia de reprodução de Arrojadoa rhodantha?

\section{MATERIAL E MÉtodos}

As observações da fenologia e biologia floral de Arrojadoa rhodantha foram feitas em uma área de 600 ha de Caatinga arbustiva-arbórea, hiperxerófila, na Estação Experimental da Caatinga, Embrapa Semiárido (09 $09^{\prime} \mathrm{S}, 40^{\circ} 22^{\prime} \mathrm{W}, 350$ m s.n.m. e média pluviométrica anual de $570 \mathrm{~mm}$ ), município de Petrolina, Pernambuco. Segundo a classificação de Köeppen, o clima da região é do tipo BSwh', definido como semiárido (chuva anual menor que $750 \mathrm{~mm}$ ), de vegetação xerófita (BS), apresentando inverno seco (w), temperatura do mês mais frio maior que $18^{\circ} \mathrm{C}\left(\mathrm{h}^{\prime}\right)$, sem excesso hídrico. O período chuvoso concentra-se entre os meses de novembro a abril, com 90\% dos totais anuais (Teixeira 2010).

O acompanhamento da fenologia foi realizado entre agosto de 2010 e julho de 2011, utilizando 15 indivíduos marcados de Arrojadoa rhodantha, acompanhados semanalmente, anotando-se a presença ou ausência das fenofases de floração e de frutificação. O pico de um determinado evento fenológico foi considerado quando mais de $50 \%$ dos indivíduos apresentaram a mesma fenofase (Morellato et al. 1989). Quanto à morfologia, cinco botões de dois indivíduos foram marcados e acompanhados por cerca de 10 dias para verificar alterações de formato. Flores $(n=10)$ também foram coletadas em campo e analisadas em laboratório para medidas do comprimento e diâmetro floral, posição das estruturas reprodutivas no interior do tubo floral, bem como a altura e o diâmetro da câmara nectarífera. A coloração da flor e das estruturas reprodutivas foi identificada de acordo com Munsell Color (1977). O horário e a longevidade floral foram registrados em 15 flores marcadas em pré-antese e acompanhadas até a senescência. Para se verificar o número de flores produzidas por pseudocefálio/dia, 10 pseudocefálios foram marcados e acompanhados em cinco indivíduos. 
A receptividade do estigma foi checada com peróxido de hidrogênio a 10 vol. (Zeisler 1938), em botões em pré-antese $(n=10)$ e em flores avaliadas nos horários de 09h00 $(n=10)$, $10 \mathrm{~h} 00(\mathrm{n}=10)$ e $11 \mathrm{~h} 00(\mathrm{n}=10)$. Para se avaliar a viabilidade dos grãos de pólen, cinco lâminas foram preparadas segundo Radford et al. (1974), utilizando uma antera de cada botão $(\mathrm{n}=5)$ em pré-antese, de três indivíduos. Para estimar a produção de pólen/antera, lâminas foram preparadas com uma antera de botões em pré-antese $(n=10)$ coradas com Carmin Acético 1,2\% (Radford et al. 1974), e o número total de grãos de pólen foi contabilizado com auxílio de contador manual. O número encontrado para cada antera foi multiplicado pelo número médio de estames encontrados nas flores $(\mathrm{n}=10)$, estimando-se a produção de grãos/flor. O número de óvulos foi contabilizado em 10 flores de cinco indivíduos.

Para avaliar o volume total de néctar produzido por flor/dia, 10 flores em pré-antese foram ensacadas e coletadas ao fim da manhã. $O$ volume de néctar foi avaliado com auxílio de seringas de insulina de $1 \mathrm{ml}$ e a concentração de açúcares do néctar foi avaliada com um refratômetro digital Hanna HI (0-85\%).

Para determinar o sistema reprodutivo da espécie, flores foram submetidas aos testes de autopolinização manual e espontânea, polinização manual cruzada e agamospermia. Para cada tratamento, foram utilizadas 20 flores, selecionadas nos 15 indivíduos da população estuda, sendo estas previamente ensacadas e emasculadas quando necessário. O pólen utilizado em todos os testes foi obtido de flores previamente protegidas com saco de papel. Para os experimentos de polinização cruzada, foram utilizadas plantas localizadas a pelo menos $5 \mathrm{~m}$ dos indivíduos receptores. Também foram marcadas e observadas 20 flores sem nenhum tratamento para determinar o sucesso da polinização em condições naturais, servindo como controle. Os frutos obtidos foram acompanhados até a maturação, quando foi feita a avaliação morfológica dos mesmos. As frequências de frutos formados foram comparadas aplicando o teste estatístico de Qui-quadrado $\left(\chi^{2}\right)$. Também foram calculados a relação pólen/óvulo e o índice de cruzamento, de acordo com Cruden (1977), como indicativo do sistema de reprodução.

Frutos formados em condições naturais $(n=5)$ foram acompanhados a partir do fechamento da flor até o completo desenvolvimento. A avaliação da formação de sementes por fruto foi feita em 10 frutos coletados ao acaso. A razão semente/óvulo foi calculada com base na média de sementes obtida nesses frutos e na média de óvulos encontrada nas flores observadas para as avaliações de morfologia floral. 
Os visitantes florais foram observados em dias não consecutivos, nos meses de maior intensidade de floração (novembro e dezembro de 2010 e fevereiro e dezembro de 2011), no período de $05 \mathrm{~h} 00$ às $11 \mathrm{~h} 00$, sendo anotados a frequência, a duração e o horário das visitas, bem como o comportamento dos visitantes mais frequentes. Para cada intervalo de observação com duração de uma hora (p. ex., 05 h00 às 06h00), foram feitas pelo menos cinco repetições, totalizando $35 \mathrm{~h}$ de esforço amostral.

De acordo com o comportamento apresentado, os visitantes foram considerados como polinizadores (Dafni 1992), pilhadores ou furtadores (Inouye 1980). Quanto à sua frequência de visitas florais, os visitantes foram classificados em abundantes (frequências de visitas superiores a $30 \%$ ), frequentes (entre $10 \%$ e $30 \%$ ) e raros (inferiores a $10 \%$ ). Os visitantes capturados foram montados em alfinetes entomológicos e preservados a seco, para posterior identificação e exame dos locais de deposição do pólen; o material encontra-se depositados na coleção do Laboratório de Ecologia do Trópico Semiárido (LETSA) da Embrapa Semiárido.

\section{RESUltados E Discussão}

Distribuição e fenologia. Arrojadoa rhodantha é uma espécie de ampla distribuição na Caatinga, com ocorrência registrada para os estados do Piauí, Pernambuco, Bahia e Minas Gerais (Zappi et al. 2010). Na área de estudo, os indivíduos foram encontrados tanto em ambientes mais fechados e sombreados como em locais abertos.

As fenofases de floração e frutificação foram registradas ao longo de todo ano, com maior produção de flores no período de novembro a fevereiro (Figura 1). Os picos de produção de frutos, geralmente ocorreram um mês após o pico de floração. Em Betânia, Pernambuco, Lima (2007) encontrou padrão semelhante de floração e frutificação em cinco espécies de cactáceas, entre elas Arrojadoa rhodantha. Ele comentou que essa produção contínua de flores e frutos poderia ser atribuída a adaptações dessas plantas a condições climáticas severas, como armazenamento de água no caule, ausência de folhas e metabolismo tipo CAM, permitindo sua floração e frutificação independente das chuvas. Nesse mesmo trabalho (Lima 2007), foi registrado padrão contínuo, subanual e irregular de floração e frutificação para A. rhodantha e Pilosocereus gounellei, com maior proporção de indivíduos nessas fenofases durante a transição da estação seca para a chuvosa, concordando com o observado para $A$. rhodantha no presente estudo. 
A produção contínua de flores ao longo do ano indica que Arrojadoa rhodantha pode ser considerada uma importante fonte de néctar e pólen para os visitantes florais, entre eles os beija-flores, concordando com as observações feitas para outras cactáceas (Colaço et al. 2006; Leal et al. 2006; Quirino et al. 2006; Fonseca et al. 2008). Estudos em comunidades de espécies ornitófilas na Caatinga (Leal et al. 2006; Las-Casas 2009) e em Mata Atlântica (Buzzato 1995) mostraram que há predominância de espécies anuais, porém destacam que as espécies com floração contínua, embora em menor número, são importantes para a guilda de beija-flores. Segundo Machado \& Lopes (2003), a produção constante de recursos florais ao longo do ano na Caatinga, onde há sazonalidade de recursos, viabiliza a manutenção das espécies de beija-flores residentes.

Morfologia e biologia floral. Os botões florais de Arrojadoa rhodantha estão inseridos em pseudocefálios no ápice dos ramos ou entre as articulações do caule, podendo estar agrupados em número de dois a onze. Eles podem levar 6-8 dias para completar o desenvolvimento e, no estádio final, apresentam 27,11 $\pm 3,54 \mathrm{~mm}$ compr. $(\mathrm{n}=8)$. No estádio inicial (estádio I), o botão ainda está revestido por lanugem, não sendo possível visualizar as tépalas florais (Figura 2a). Nos $2^{\circ}$ e $3^{\circ}$ dias (estádio II), o botão não está mais coberto por lanugem, tornando visíveis os seguimentos do perianto. Somente a partir do $5^{\circ}$ dia (estádio III), o botão apresenta formato tubular (Figura 2b), cujo comprimento total é atingido por volta do $7^{\circ}$ e $8^{\circ}$ dias (estádio IV). Ao longo do desenvolvimento do botão não foi observada alteração da coloração.

As flores são actinomorfas, monoclinas, gamotépalas, tubulosas, 40,31 $\pm 1,39 \mathrm{~mm}$ compr., 11,22 $\pm 1,29$ mm diâm. A câmara nectarífera localiza-se na porção basal da flor, tem $9,25 \pm 0,66 \mathrm{~mm}$ larg. e 10,17 $\pm 0,72 \mathrm{~mm}$ de altura. O androceu é composto por vários estames $(365 \pm 49,34 ; n=10)$, filiformes, aderidos ao tubo floral, com anteras bitecas de deiscência longitudinal, basifixas, que produzem, em média, 1.702,4 grãos de pólen $(\mathrm{n}=10)$, estimandose 628.300,4 grãos/flor. O gineceu é formado por um ovário ínfero, unilocular, plurilovulado $(608 \pm 153$ óvulos, $\mathrm{n}=10)$ e estigma com $(6-) 8(9)$ lobos. As tépalas apresentam coloração magenta (5RP 5/10), as anteras apresentam cor creme (5y 8/10) e o estigma é branco.

De acordo com o padrão de tipos florais descrito para a Caatinga por Machado \& Lopes (2003), as flores de Arrojadoa rhodantha podem ser classificadas como muito grandes ( $>$ de $30 \mathrm{~mm}$ ), tubulosa, radiais e com órgãos reprodutivos abrigados no interior do tubo floral. As autoras verificaram que espécies com flores grandes e muito grandes $(54,1 \%)$ ou tubulosas $(22,9 \%)$ são bem representadas nesse ecossistema. Entretanto, quanto à coloração, o 
inverso foi observado, pois flores rosa (incluindo rosa-claras e rosa-choque - 6,4\%) são pouco frequentes nesse tipo de vegetação, onde predominam as flores amarelas e brancas. As autoras comentaram, também, que a ornitofilia está bem representa na Caatinga (15\%), sendo a polinização por insetos a mais frequente $(69,9 \%)$.

As flores de Arrojadoa rhodantha encontram-se totalmente abertas por volta das 04h00, quando as tépalas estão afastadas, evidenciando o interior do tubo floral (Figura 2c). O pólen encontra-se disponível e viável $(98,1 \%$ ) e o estigma, receptivo desde a fase de botão floral em pré-antese (estádio IV). A produção de néctar ocorre desde o início da antese, quando é possível visualizar a presença de líquido viscoso e transparente. Nas flores ensacadas, foi encontrado $0,20 \pm 0,06 \mathrm{ml}$ de néctar/dia, com concentração de $26,07 \pm 1,21 \%$ ( $n=10)$; volume e concentração similares aos encontrados em cactáceas ornitófilas (Locatelli \& Machado 1999a; Colaço et al. 2006).

As flores permanecem sem alterações visuais até às $10 \mathrm{~h} 30$, quando inicia o processo de fechamento do tubo floral e a desidratação dos segmentos do perianto, caracterizando o início da senescência floral. Por volta das $11 \mathrm{~h} 30$, o tubo floral está flácido, as estruturas reprodutivas estão desbotadas e a entrada da flor está parcialmente fechada. A longevidade floral é de aproximadamente $7 \mathrm{~h}$ e, $24 \mathrm{~h}$ após a antese, as flores encontram-se totalmente fechadas e adquirem aspecto similar a um botão em pré-antese. A permanência das flores fechadas sem alteração da cor pode manter a atratividade visual, uma vez que a maioria dos cefálios apresenta poucas flores (2-4), sendo raros os que possuem mais de cinco botões. Com isso, os cefálios de Arrojadoa rhodantha ficariam mais atrativos aos visitantes, que uma vez próximos, poderiam visitar as flores que ainda estão funcionais.

Decorridas $48 \mathrm{~h}$ após a antese, as flores começam a ficar enegrecidas no ápice, independentemente da formação ou não do fruto. O tubo floral encontra-se completamente preto, e desidratado somente $72 \mathrm{~h}$ após a antese, e o desenvolvimento do ovário nas flores fecundadas só é visualizado de 96-120h após a antese (Figura 2d).

Por apresentar atributos florais como antese diurna, néctar abundante e concentrado, tubo floral rígido e nectário distante do estigma e das anteras, as flores de Arrojadoa rhodantha podem ser consideradas ornitófilas (cf. Faegri \& van der Pij1 1979), de acordo com a indicação feita para o gênero (Taylor \& Zappi 2004). Espécies ornitófilas são bem representadas na Caatinga, com destaque para as famílias Acanthaceae, Bromeliaceae, Cactaceae, Leguminosae, Passilforaceae e Sterculiaceae (Machado \& Lopes 2003). Entre as 
cactáceas da Caatinga, a ornitofilia foi registrada para espécies de Melocactus (Colaço et al. 2006; Romão et al. 2007) e Tacinga (Locatelli \& Machado 1999a).

Sistema de reprodução. Na Tabela 1, são apresentados os resultados obtidos nos testes realizados para Arrojadoa rhodantha e mostram que houve formação de frutos apenas em condições naturais e por polinização cruzada. A análise estatística $\left(\chi^{2}\right)$ mostrou que há diferença significativa entre a formação de frutos a partir dos dois tratamentos, sendo que o menor número obtido por xenogamia pode ser atribuído à danos ocorridos no estigma durante a manipulação das flores para emasculação e/ou deposição de pólen. A pequena distância (5 m) entre flores doadoras e receptoras de pólen também pode ter sido a causa da menor produção de frutos a partir da polinização cruzada pelo fato dos indivíduos serem irmãos.

A taxa de frutificação em condições naturais $(55 \%)$ foi menor que a registrada para outras cactáceas (Locatelli \& Machado 1999a,b; Colaço et al. 2006; Rocha et al. 2007), sendo o comportamento predatório de Trigona spinipes (veja o tópico visitantes florais), um dos fatores que podem ter influenciado negativamente no sucesso reprodutivo. A ausência de frutos nos experimentos de autopolinização espontânea e manual indica que Arrojadoa rhodantha é alógama e, neste caso, os beija-flores seriam fundamentais para o sucesso reprodutivo dessa cactácea na área de estudo.

As razões pólen/óvulo (P/O) e semente/óvulo (S/O) e o índice de cruzamento (IC) são apresentados na Tabela 2. Comparando os valores encontrados para P/O e IC com a tabela de Cruden (1977), Arrojadoa rhodantha seria classificada como uma espécie xenogâmica facultativa, discordando com os dados obtidos nos experimentos de polinização. A razão S/O foi baixa e, de acordo com Bawa \& Buckley (1989), também seria um indicativo de que a espécie é alógama por estar distante de 1, valor esperado em espécies autógamas.

Os frutos de Arrojadoa rhodantha são carnosos, do tipo baga, subglobosos, indeiscentes, apresentam coloração rósea e mantém o perianto enegrecido aderido em sua superfície. O fruto leva cerca de 30 dias para completar sua maturação, atingindo $15,7 \pm 2,0$ mm compr., 16,4 $\pm 1,35 \mathrm{~mm}$ larg. e pesando 3,25 $\pm 0,56 \mathrm{~g}(\mathrm{n}=5)$. As sementes são pequenas ( 1 mm diâm.), negras, numerosas (368,9 $\pm 179,37$ sementes/fruto), envoltas em polpa incolor, de consistência viscosa e sabor adocicado, concordando com o padrão descrito para a família (Zappi 1992).

Visitantes florais e comportamento de visita. Ao longo das observações, as flores foram visitadas por beija-flores (3 espécies), abelhas (3), moscas (1) e borboletas (1). As abelhas foram os visitantes mais frequentes, responsáveis por $93,16 \%$ do total de visitas, 
indicando que esta cactácea pode ser considerada uma fonte de pólen para esses insetos, e de néctar, no caso de Trigona spinipes (Apidae). Os beija-flores foram responsáveis por apenas $6,18 \%$ das visitas, sendo Eupetomena macroura o mais frequente, com $74,6 \%$ do total de visitas registrado para essas aves. De acordo com a frequência de visitas, T. spinipes foi considerada abundante e as abelhas Halictidae, frequentes. Os demais visitantes florais foram considerados raros (Tabela 3).

As visitas de Trigona spinipes foram observadas de $05 \mathrm{~h} 00$ às $10 \mathrm{~h} 00$, com maior frequência entre $05 \mathrm{~h} 00$ e $07 \mathrm{~h} 00$, quando a espécie foi responsável por mais de $95 \%$ do total de visitas. As visitas de abelhas Halictidae ocorreram entre 07h00 e 11h00, com pico de visitação entre $07 \mathrm{~h} 00$ e 08h00. Abelhas Frieseomelitta doederleini foram observadas entre 06h00 e 09h00, concentrando suas visitas de 08h00 às 09h00. As visitas de Diptera $(\mathrm{n}=7)$ e da borboleta Phoebis philea $(\mathrm{n}=3)$ foram registradas de $07 \mathrm{~h} 00$ às $08 \mathrm{~h} 00$ e de $09 \mathrm{~h} 00$ às 10h00, respectivamente (Figura 3). A presença dos beija-flores foi observada a partir das 06h00: Chrysolampis mosquitus, de 09h00 às 10h00; Chlorostilbon aureoventris, em três horários ao longo da manhã, concentrando suas visitas de $10 \mathrm{~h} 00$ às $11 \mathrm{~h} 00$; e Eupetomena macroura, de $07 \mathrm{~h} 00$ às $11 \mathrm{~h} 00$, sendo mais frequentes de $10 \mathrm{~h} 00$ às $11 \mathrm{~h} 00$ (Figura 3 ).

As abelhas Frieseomelitta doederleini (Figura 4a) e Halictidae (Figura 4b) e a mosca coletaram pólen durante as visitas. Para isso, elas pousavam e dirigiam-se para a entrada do tubo floral, onde tinham acesso às anteras, expostas ou localizadas na fauce da corola, mas não o estigma, no interior da flor. Já Trigona spinipes coletava o pólen das anteras, armazenando-o nas corbículas. Durante o forrageio, a abelha dilacerava as tépalas internas e os estames (Figura 4c) e, em alguns casos, cortava o estigma. Raras vezes, a abelha cortou todos os estames, chegando à câmara nectarífera, podendo coletar o néctar ali acumulado. Em alguns casos, observou-se T. spinipes no centro da flor, fechando a entrada do tubo e impedindo que outras abelhas pousassem ou que os beija-flores tivessem acesso ao tubo floral. Lembrando que as visitas dessas abelhas se concentraram nas primeiras horas da manhã, este comportamento pode ser prejudicial à polinização, pois além de danificar as estruturas reprodutivas, deixando as flores menos atrativas, $T$. spinipes também pode inibir a aproximação de outros visitantes. Comportamento similar foi descrito em flores de Melocactus por Colaço et al. (2006), que também consideraram a possibilidade das visitas dessas abelhas comprometerem a polinização, tornando as flores menos atraentes à visitação de outros insetos e/ou vertebrados. 
A borboleta Phoebis philea apresentou comportamento de coleta de néctar, pousando sobre a extremidade do tubo floral (Figura 4d), distendendo a probóscide e introduzindo-a no interior do tubo para ter acesso à câmara nectarífera, sem contudo tocar o estigma. Os beijaflores, por outro lado, apresentaram comportamento de coleta de néctar em voos rápidos e adejados, introduzindo o bico no interior do tubo floral (Figura 4e e f). Nessas ocasiões, as aves tocavam as estruturas reprodutivas, ficando o pólen depositado tanto na parte superior como na inferior do bico, e na fronte.

Com base nesses comportamentos, as abelhas Halictidae e Frieseomelitta doederleini e a mosca foram consideradas furtadores de pólen e Phoebis philea furtadora de néctar, enquanto Trigona spinipes, pelos danos causados às flores, foi considerada pilhadora de pólen e/ou néctar. De acordo com o comportamento e frequência observadas, Eupetomena macroura, Chlorostilbon aureoventris e Chrysolampis mosquitus foram consideradas polinizadoras potenciais por tocarem as estruturas reprodutivas, sendo E. macroura a espécie mais frequente. Essas aves também são relatadas como polinizadoras de espécies de Melocactus e Tacinga (Locatelli \& Machado 1999a; Colaço et al. 2006), indicando comportamento generalista (Machado \& Lopes 2003) e confirmando sua importância na polinização de cactáceas (Leal et al. 2006).

Diante dos resultados obtidos aqui, conclui-se que Arrojadoa rhodantha apresenta atributos florais característicos de espécies ornitófilas, sendo Eupetomena macroura, Chlorostilbon aureoventris e Chrysolampis mosquitus seus polinizadores potenciais no sítio de estudo. Por apresentar floração e frutificação ao longo de todo ano, a espécie pode ser considerada uma importante fonte alimentar para a fauna da Caatinga, onde a oferta de recursos alimentares é sazonal.

\section{AgRADECIMENTOS}

C.T.V.D. Martins e T.A. Silva agradecem a FACEPE e ao PROBIO, respectivamente, pela concessão das bolsas de Apoio Técnico.

\section{REFERÊNCIAS}

Aona, L.Y.S.; Machado, M.; Pansarin, E.R.; Castro, C.C.; Zappi, D. \& Amaral, M.C.E. 2006. Pollination biology of three Brazilian species of Micranthocereus Backeb. (Cereeae, Cactoideae) endemic to the "campos rupestres". Bradleya 24: 39-52. 
Bawa, K.S. \& Buckley, D.P. 1989. Seed: ovule ratios, selective abortion and mating systems in Leguminosae. In: C.H. Stirton \& J.L. Zaruchi (eds), Advances in Legume Biology. Monographs in Systematic Botany from the Missouri Botanical Garden 29: 243-262.

Buzzato, S. 1995. Estudo Comparativo de Flores Polinizadas por Beija-flores em Três Comunidades da Mata Atlântica no Sudeste do Brasil. Tese de Doutorado. Universidade Estadual de Campinas.

Colaço, M.A.S.; Fonseca, R.B.S.; Lambert, S.M.; Costa, C.B.N.; Machado C.G. \& Borba, E.L. 2006. Biologia reprodutiva de Melocactus glaucescens Buining \& Brederoo e M. paucispinus G. Heimen \& R. Paul (Cactaceae), na Chapada Diamantina, Nordeste do Brasil. Revista Brasileira de Botânica 29: 239-249.

Cruden, R.W. 1977. Pollen-ovule ratios: a conservative indicator of breeding systems in flowering plants. Evolution 31: 32-46.

Dafni, A. 1992. Pollination Ecology: a practical approach. The practical approach series. Oxford University Press, Oxford.

Faegri, K. \& van der Pijl, L. 1979. The Principles of Pollination Ecology. Pergamon Press, London.

Fonseca, R.B.S.; Funch, L.S. \& Borba, E.L. 2008. Reproductive phenology of Melocactus (Cactaceae) species from Chapada Diamantina, Bahia, Brazil. Revista Brasileira de Botânica 31: 237-244.

Hunt, D.R.; Taylor, N.P. \& Charles, G. 2006. The New Cactus Lexicon. Vol. 2. Text \& Atlas. Dh Books, Milborne Port.

Inouye, D.W. 1980. The terminology of floral larceny. Ecology 61: 1251-1253.

Las-Casas, F.M.G. 2009. Guildas de Beija-flores (Aves: Trochilidae) em uma Área de Caatinga, no Estado de Pernambuco. Dissertação de Mestrado. Universidade Federal de Pernambuco.

Leal, F.C.; Lopes, A.V. \& Machado, I.C. 2006. Polinização por beija-flores em uma área de Caatinga no Município de Floresta, Pernambuco, Nordeste do Brasil. Revista Brasileira de Botânica 29: 379-389.

Lima, A.L.A. 2007. Padrões Fenológicos de Espécies Lenhosas e Cactáceas em uma Área do Semi-árido do Nordeste do Brasil. Dissertação de Mestrado. Universidade Federal Rural de Pernambuco. 
Locatelli, E. \& Machado, I.C.S. 1999a. Comparative study of the floral biology of two ornithophilous species of Cactaceae: Melocactus zehntneri and Opuntia palmadora. Bradleya 17: 75-85.

Locatelli, E. \& Machado, I.C.S. 1999b. Floral biology of Cereus fernambucensis: a sphingophilous cactus of restinga. Bradleya 17: 86-94.

Machado, C.G. 2009. Beija-flores (Aves: Trochilidae) e seus recursos florais em uma área de caatinga na Chapada Diamantina, Bahia, Brasil. Zoologia 26: 255-265.

Machado, I.C.S. \& Lopes, A.V. 2003. Recursos florais e sistemas de polinização e sexuais em Caatinga. In: I.R. Leal, M. Tabarelli \& J.M.C. Silva (eds), Ecologia e Conservação da Caatinga. Editora Universitária da Universidade Federal de Pernambuco, Recife, p. $515-563$.

Machado, M.C. 2009. Cactaceae. In: A.M. Giulietti, A. Rapini, M.J.G. Andrade, L.P. Queiroz \& J.M.C. Silva (orgs), Plantas Raras do Brasil. Conservação Internacional, Belo Horizonte, p. 118-126.

Morellato, L.P.C.; Rodríguez, R.R.; Leitão-Filho, H.F. \& Joly, C.A. 1989. Estudo comparativo da fenologia de espécies arbóreas de Floresta de Altitude e Floresta Mesófila Semidecídua na Serra do Japi, Jundiaí, São Paulo. Revista Brasileira de Botânica 12: 85-98.

Munsell Color 1977. Munsell Color Charts for Plant Tissues. 2 ed. Kollmorgen Corporation, Baltimore.

Porsch, O. 1939. Cactaceae. In: J. Druck (ed.), Das Bestäubungsleben der Kakteen-blüte II. Cactaceae (DKG) 1939: 81-142.

Radford, A.E.; Dickison, W.C.; Massey, J.R. \& Bell, C.R. 1974. Vascular Plant Systematics. Harper \& Row Publishers, New York.

Raw, A. 1996. Territories of the Ruby-topaz Hummingbird Chrysolampis mosquitus at flowers of the "turk's-cap" Cactus, Melocatus salvadorensis in the dry Caatinga of North-eastern Brazil. Revista Brasileira de Biologia 56: 581-584.

Rocha, E.A.; Machado, I.C. \& Zappi, D.C. 2007. Floral biology of Pilosocereus tuberculatus (Werderm.) Byles \& G.D. Rowley: a bat pollinated cactus endemic from the "Caatinga" in northeastern Brazil. Bradleya 25:125-128.

Romão, R.L.; Hughes, F.M.; Vieira, A.M.C. \& Fontes, E. C. 2007. Autoecologia de cabeça-de-frade (Melocactus ernestii Vaupel) em duas áreas de afloramentos na Bahia. Revista Brasileira de Biociências 5: 738-740. 
Taylor, N. \& Zappi, D. 2004. Cacti of Eastern Brazil. Royal Botanic Gardens, Kew.

Teixeira, A.H.C. 2010. Informações Agrometeorológicas do Polo Petrolina, PE/Juazeiro, BA - 1963 a 2009. Embrapa Semiárido, Petrolina.

Zappi, D.C. 1992. A Família Cactaceae nos Campos Rupestres da Cadeia do Espinhaço Minas Gerais, Brasil. Dissertação de Mestrado. Universidade de São Paulo, São Paulo.

Zappi, D.C.; Taylor, N. \& Machado, M. 2010. Cactaceae. In: Lista de Espécies da Flora do Brasil. Jardim Botânico do Rio de Janeiro. Disponível em http://floradobrasil.jbrj.gov.br/2010/FB001410; acesso em 30 jul. 2011.

Zappi, D.C.; Taylor, N.; Silva, R.B.; Machado, M.; Moraes, E.M.; Calvente, A.; Cruz, B.; Correia, D.; Larocca, J.; Assis, J.G.; Aona, L.; Menezes, M.O.T.; Meiado, M.; Marchi, M.N.; Santos, M.R.; Bellintani, M.; Coelho, P., Nahoum, P.I. \& Resende, S. 2011. Plano de Ação Nacional para a Conservação das Cactáceas. Instituto Chico Mendes de Conservação da Biodiversidade - ICMBIO, Brasília.

Zeisler, M. 1938. Über die Abgrenzung der Eigentlichen Narbenfläche mit Hilfe von Reaktionen. Beiheft Botanisches Zentralblatt 58: 308-318. 


\section{LEGENDAS}

Figura 1. Dados climáticos da região de Petrolina, Pernambuco, Brasil, entre agosto de 2010 e julho de 2011 (A) e dados fenológicos de Arrojadoa rhodantha em área de caatinga hiperxerófila do Estado durante este período (B).

Figura 2. Diferentes estádios dos botões e das flores de Arrojadoa rhodantha: A- $1^{\circ}$ dia botão recoberto com lanugem; B- $7^{\circ}$ dia - botão tubuloso (à direita); C- $8^{\circ}$ dia - flor totalmente aberta, mostrando estames e parte do estigma na porção central (seta); D- flor $72 \mathrm{~h}$ após a antese (à esquerda); ovário em desenvolvimento (seta).

Figura 3. Proporção de visitas por visitante floral, em intervalo de $1 \mathrm{~h}$ no período da manhã, registrada em flores de Arrojadoa rhodantha de uma área de caatinga hiperxerófila, Petrolina, Pernambuco, Brasil.

Figura 4. Visitantes florais em Arrojadoa rhodantha: A- Friseomelitta doederleini; BHalictidae; C- Trigona spinipes; D- Phoebis philea; E- Clorostilbon aureoventris; FEupetomena macroura. 
Tabela 1. Resultados dos experimentos de polinização de Arrojadoa rhodantha em caatinga hiperxerófila, Petrolina, Pernambuco, Brasil.

\begin{tabular}{llll}
\hline Experimento de polinização & $\mathbf{N}^{\mathbf{0}}$ de flores & $\mathbf{N}^{\mathbf{0}}$ de frutos & $\mathbf{\%}$ \\
\hline Condições naturais/Controle & 20 & $11^{\mathrm{a}}$ & 55,0 \\
Apomixia & 20 & 0 & 0 \\
Autopolinização espontânea & 20 & 0 & 0 \\
Autopolinização manual & 20 & 0 & 0 \\
Polinização cruzada & 17 & $6^{\mathrm{b}}$ & 35,3 \\
\hline
\end{tabular}

Valores seguidos de mesma letra na coluna não diferem pelo teste qui-quadrado, com 1 grau de liberdade e $\alpha=5 \%$. 
Tabela 2. Razão pólen/óvulo e semente/óvulo e índice de cruzamento de Arrojadoa rhodantha em caatinga hiperxerófila, Petrolina, Pernambuco, Brasil.

\begin{tabular}{ll}
\hline Descrição & Valor obtido \\
\hline Razão Pólen/Óvulo & $1.033,39$ \\
Razão Semente/Óvulo & 0,61 \\
Índice de cruzamento & 3 \\
\hline
\end{tabular}


Tabela 3. Visitantes florais de Arrojadoa rhodantha com número de visitas, \%, frequência, recurso forrageado e classificação, observados em caatinga hiperxerófila, Petrolina, Pernambuco, Brasil. $\mathrm{PPT}=$ polinizador potencial, $\mathrm{FN}=$ furtador de néctar, $\mathrm{FP}=$ furtador de pólen, $\mathrm{PP}=$ pilhador de Pólen, $\mathrm{PN}=$ pilhador de néctar.

\begin{tabular}{|c|c|c|c|c|}
\hline Visitantes Florais & Visitas (n) & $\%$ & Recurso Floral & Classificação \\
\hline \multicolumn{5}{|l|}{ INSETOS } \\
\hline \multicolumn{5}{|l|}{ Hymenoptera } \\
\hline Halictidae & 449 & 29,54 & Pólen & FP \\
\hline $\begin{array}{l}\text { Apidae } \\
\text { Trigona spinipes (Fabricius, 1973) }\end{array}$ & 931 & 61,25 & Pólen/Néctar & $\mathrm{PP} / \mathrm{PN}$ \\
\hline Frieseomelitta doederleini (Friese, 1900) & 36 & 2,37 & pólen & FP \\
\hline Diptera & 7 & 0,45 & pólen & FP \\
\hline \multicolumn{5}{|l|}{ Lepidoptera (Pieridae) } \\
\hline Phoebis philea (Linnaeus, 1763) & 3 & & & \\
\hline \multicolumn{5}{|l|}{ AVES (Apodiformes, Trochilidae) } \\
\hline $\begin{array}{l}\text { Chlorostilbon aureoventris (d'Orbigny \& } \\
\text { Lafresnaye, 1838) }\end{array}$ & 21 & 1,38 & néctar & \\
\hline Eupetomena macroura (Gmelin,1788) & 70 & 4,61 & néctar & PPT \\
\hline Chrysolampis mosquitus (Linnaeus, 1758) & 3 & 0,20 & néctar & PPT \\
\hline TOTAL & 1520 & 100 & & \\
\hline
\end{tabular}




$$
a^{e^{+0}}
$$


Sitientibus série Ciências Biológicas 12(2)

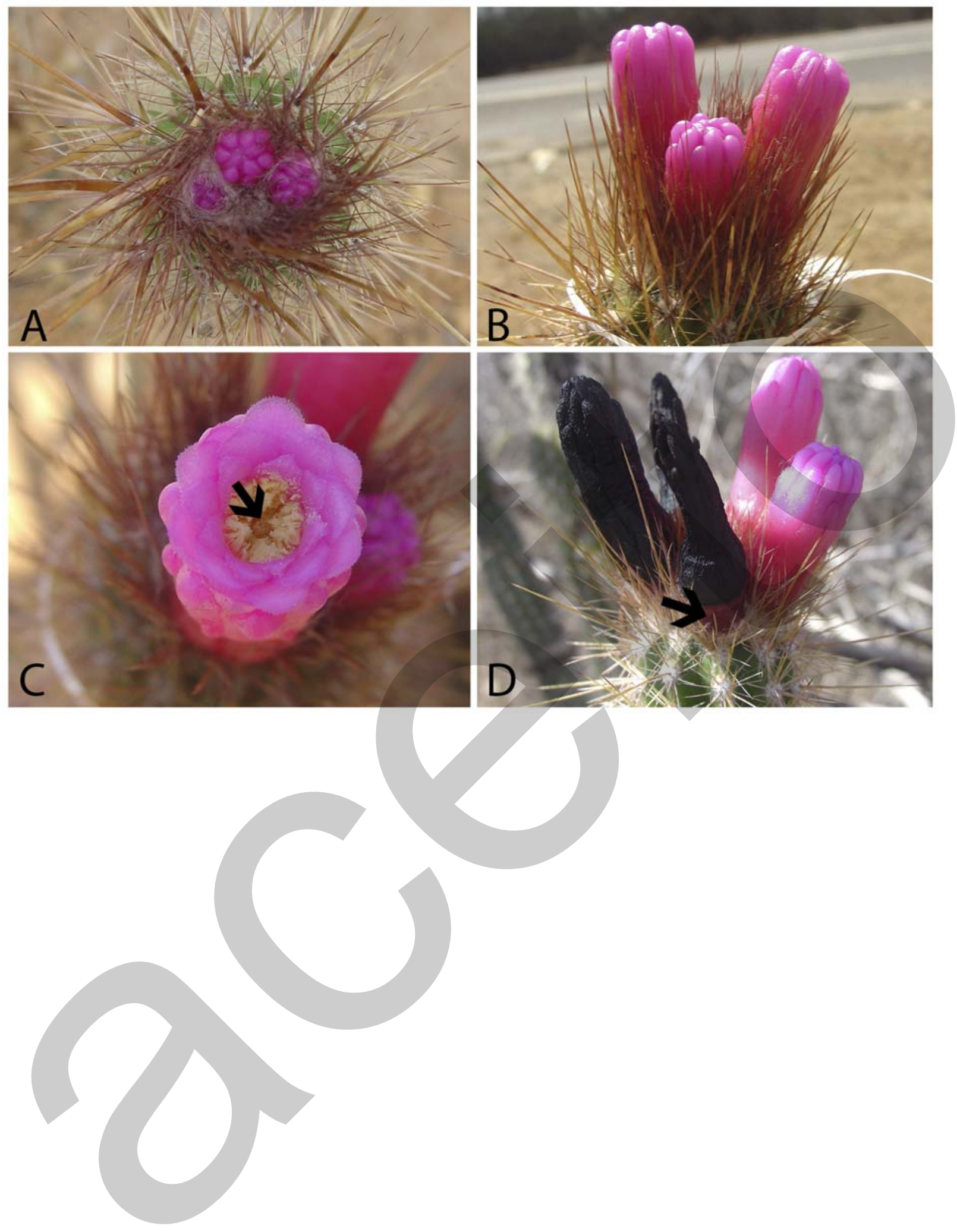


Sitientibus série Ciências Biológicas 12(2)

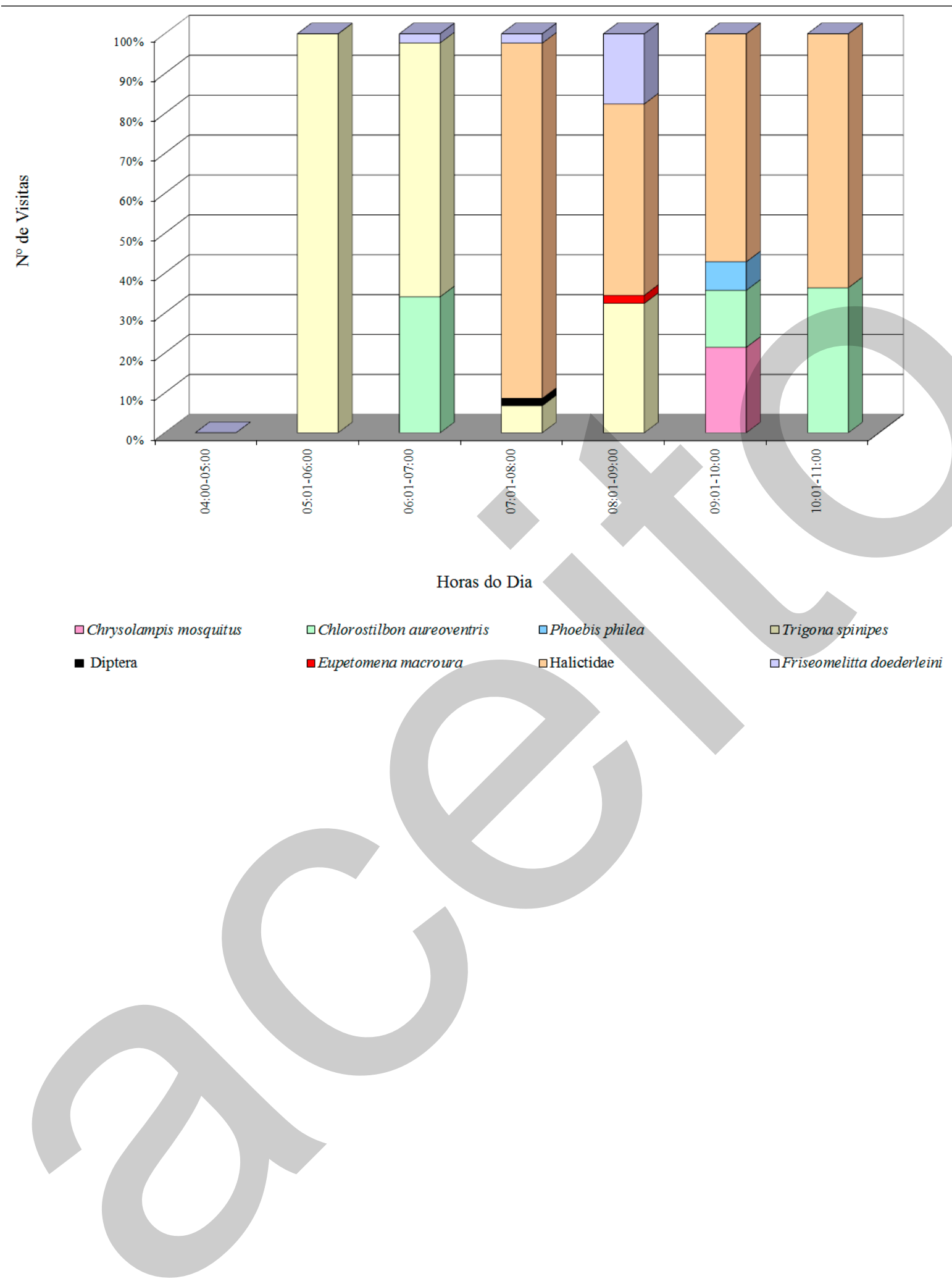


Sitientibus série Ciências Biológicas 12(2)
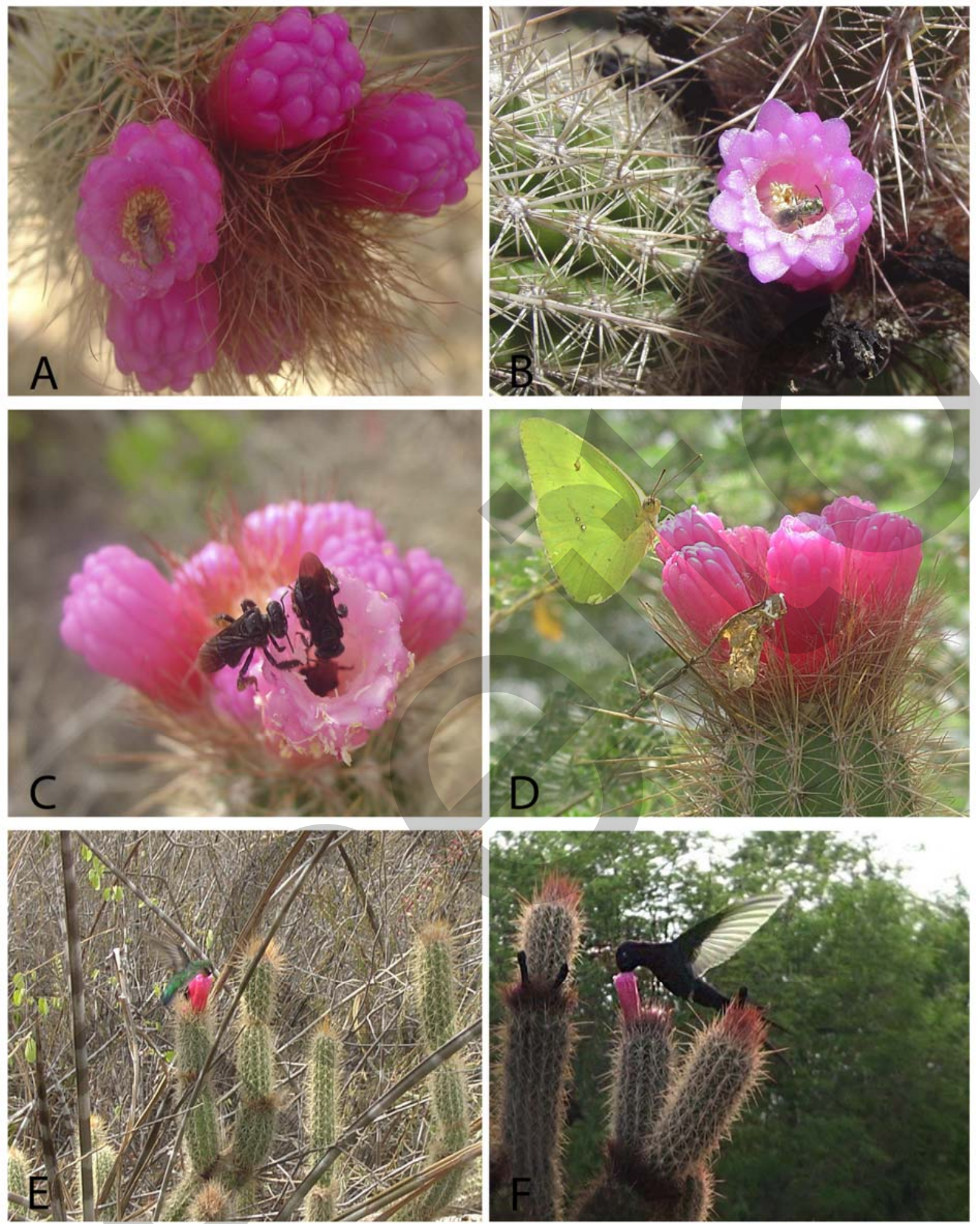